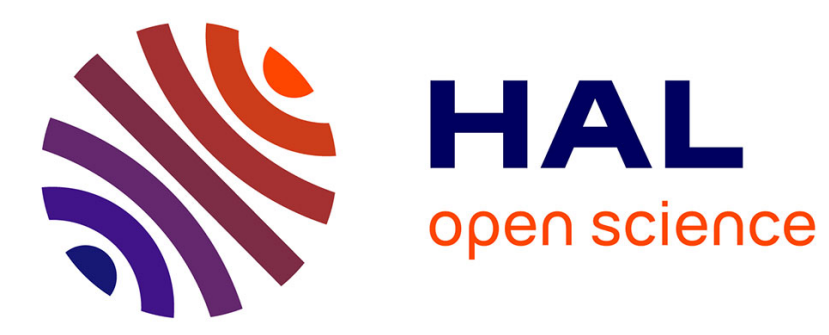

\title{
What Is Quantum Crystallography?
}

Francesca Rita Novara, Alessandro Genoni, Simon Grabowsky

\section{To cite this version:}

Francesca Rita Novara, Alessandro Genoni, Simon Grabowsky. What Is Quantum Crystallography?.

ChemViews, 2018, 10.1002/chemv.201800066 . hal-02196512

\section{HAL Id: hal-02196512 \\ https://hal.univ-lorraine.fr/hal-02196512}

Submitted on 28 May 2020

HAL is a multi-disciplinary open access archive for the deposit and dissemination of scientific research documents, whether they are published or not. The documents may come from teaching and research institutions in France or abroad, or from public or private research centers.
L'archive ouverte pluridisciplinaire HAL, est destinée au dépôt et à la diffusion de documents scientifiques de niveau recherche, publiés ou non, émanant des établissements d'enseignement et de recherche français ou étrangers, des laboratoires publics ou privés. 


\section{INTRODUCTION}

The term "quantum crystallography" is becoming increasingly popular in physical chemistry. However, its meaning is not completely clear. Dr. Francesca Novara spoke for ChemViews Magazine with Professor Simon Grabowsky (pictured left), University of Bremen, Germany, and Dr. Alessandro Genoni, CNRS-Université de Lorraine, Nancy, France, about their definition of and fascination with quantum crystallography and the future of this emerging field.

In the mid-1990s, the term quantum crystallography was introduced by Lulu Huang, Jerome Karle, and Lou Massa for methods that use crystallographic information to improve quantum mechanical calculations and the information gained from them. Today, quantum crystallography is understood much more broadly: Its applications range from materials science over biology to theoretical calculations and simulations, involving X-ray, neutron and electron diffraction as well as Compton scattering.

\section{How would you describe what quantum crystallography is to a scientist not familiar with the field?}

Alessandro: This is a challenging question considering that scientists that work in the field have not yet established an agreed definition. Discussions about the meaning of the term itself have started to intensify and providing a definition is one of the goals of the recently established "Commission on Quantum Crystallography" of the International Union of Crystallography (IUCr).

Simon: I would say that at this stage of the ongoing discussion, we can summarize that quantum crystallography is evolving as a new science. Quantum phenomena, such as chemical bonding, are investigated using an amalgamation of diffraction measurements and theory.

Alessandro: If I had to give a definition today, I would describe quantum crystallography as the science that exploits the laws of quantum mechanics to investigate properties and phenomena which are mainly related to crystalline matter.

Simon: Parts of what is now understood as quantum crystallography by the IUCr have been successful for 50 years or more under the umbrella of "charge, spin and momentum density". These densities are more directly measurable via diffraction experiments than wavefunctions, but they are restricted in their information contents in comparison to wavefunctions. Now that wavefunctionbased modeling of diffraction data has become a mature field, it is consequent to merge these two streams under the term "quantum crystallography", and exploit their synergies for exciting applications.

\section{What is the most fascinating aspect of quantum crystallography, in your opinion?}

Alessandro: Mainly the fact that quantum mechanics allows us to penetrate into details of matter. Unlike traditional crystallography, quantum crystallography uses quantum-mechanical principles and concepts to go beyond the sheer determination of structures. It provides intrinsically quantummechanical quantities on the basis of diffraction or scattering experiments, for example, electron densities and wave functions. These quantities are fundamental if we really want to investigate the bonding and properties of crystalline systems on the basis of their electronic structure. They are also important if we want to make reliable predictions, which could lead to the design of new materials 
or drugs with a possible impact on our everyday life.

Simon: I would like to highlight that we are actually not mainly interested in the crystalline features of the materials. We are interested in the quantum phenomena inside the matter. Crystallography provides a chance to make these quantum effects observable since it magnifies the effects of single molecules due to the symmetric arrangement of the molecules inside the crystal. We can basically focus on the sub-atomic electronic properties of the molecules because they have crystallized. This is fascinating to me.

\section{What prompted you to prepare the concept article "Quantum Crystallography: Current Developments and Future Perspectives"?}

Simon: It was Alessandro's idea to organize a discussion meeting about wave function-fitting techniques. He asked me if I wanted to co-organize it with him. During the discussions between the two of us when we started organizing, it became clear that the very meaning of quantum crystallography was completely unclear. This is what we wanted to change.

Alessandro: Yes, the spark has obviously been the CECAM Discussion Meeting "Quantum Crystallography: Current Developments and Future Perspectives" held in Nancy, France, in June 2017. All 20 participants of the discussion meeting became authors of the paper.

With the article reporting the outcome of the meeting [1], we want to present the state of the art of current discussions to the scientific community-not only to our own community-and, consequently, advertise the "brand" of quantum crystallography. Our goal is to attract more and more people to this field of science, not to give a definition for specialists in which only a few scientists can contextualize their domain of research.

Simon: To be successful, we need to involve specialists that come from fields in the periphery of the solid-state chemistry community.

Alessandro: I hope that at the next CECAM Meeting on Quantum Crystallography, we will be able to also attract people with other backgrounds than crystallographers and/or quantum chemists, who can demonstrate how the techniques developed within quantum crystallography helped them for their science.

\section{Is quantum crystallography only limited to solid-state systems?}

Alessandro: Of course, the natural realm of quantum crystallography is the study of crystalline systems, but we have to bear in mind that quantum crystallography is also deeply associated with scattering. So, for example, a fascinating extension of the field could be towards the study of isolated (macro)molecules that nowadays can be also investigated through $\mathrm{X}$-ray free electron lasers.

Simon: The techniques and software developed by quantum crystallographers for solid-state applications can potentially be extended to single-molecule diffraction, imaging, scattering from thin layers, etc. 
Where do you see quantum crystallography in five years? In which fields will this science have found more applications?

Alessandro: First of all, I hope that a clear and agreed definition will be available soon. And, of course, I would like to see quantum crystallography as a more established field of science, with its methods and approaches recognized as fundamental tools to investigate crystalline matter. But, more importantly, I hope that quite soon, more and more scientists will consider themselves "quantum crystallographers".

Simon: Here, I have to disagree with you to some extent, Alessandro. I don't think that a clear and agreed definition will actually help to make the field grow and prosper. Of course, we need to be clear about the core disciplines, but if the field is fuzzy at the borders, more innovation can happen. I am not a particularly big fan of the attempt to define quantum crystallography within IUPAC or similar entities. I hope that in five years, quantum crystallography will be part of the methodological canon of inorganic, organic, and physical chemists, biochemists, mineralogists, etc.

\section{If the Nobel Committee for Chemistry were to decide to award a Nobel Prize in "Quantum Crystallography", who should receive it in your opinion? Possibly someone among your co- authors?}

Alessandro: Actually, in 2013 the Royal Swedish Academy of Science-the same institution that awards the Nobel Prizes-has awarded the Gregori Aminoff Prize to two renowned scientists in our community: Carlo Gatti, who is among the co-authors of our article, and Mark Spackman. So, they are certainly on my shortlist.

However, I would also include Dylan Jayatilaka, another co-author of our concept article. From the theoretical point of view, he is the real inventor of two original quantum crystallographic techniques that, in my opinion, will be more and more widely used in the near future: The X-ray-constrained wave function-fitting approach and, above all, the powerful Hirshfeld Atom Refinement technique.

Simon: I agree, Alessandro. But we should also remember that quantum crystallography is the basis of quantitative convergent beam electron diffraction (Q-CBED) or electron tomography. There are researchers in electron diffraction, such as Dwayne Miller or Lukas Palatinus or Philip Nakashimaanother co-author of the paper-whose work is highly significant. The same holds for all the new work on protein crystallography with free electron lasers, e.g., the work by Henry Chapman. We should also mention Piero Macchi who promoted the establishment of the new $\mathrm{IUCr}$ commission and is leading most of the community efforts to popularize quantum crystallography.

\section{In your opinion, which scientists can be considered the pioneers in this field?}

Alessandro: According to its original definition, the pioneers of quantum crystallography are undoubtedly William Clinton and Lou Massa-another co-author of the paper. They have been the first scientists to propose a technique able to extract a density matrix, which is a completely quantum-mechanical object, from X-ray diffraction data.

If we go beyond the original definition, the role of founding fathers should be also assigned to Bob 
Stewart and Philip Coppens-another Aminoff Prize laureate. They were not only the developers of the most widely-used method to determine electron densities from X-ray data, but also two scientists that, with their always original and sharp ideas, have significantly influenced and shaped the charge-density community until today.

\section{How did you enter this field of research? Was it a coincidence, passion, a strategic decision, or something else?}

Simon: I am a trained chemist and crystallographer who did experimental electron-density work during my Ph.D. After that, I actively sought to broaden my horizon in quantum mechanics to combine laboratory chemistry and computer chemistry for my future career. I got to know about Dylan Jayatilak's work at UWA [the University of Western Australia] in Perth, Australia, about X-rayconstrained wave functions. This seemed to me the ideal bridge between my expertise developed during my Ph.D. in Berlin, Germany, and my future ambition. So I wrote a so-called "Discovery Project" to the Australian Research Council, which was successful, and stayed with Dylan Jayatilaka and Mark Spackman in Perth for nearly four years.

Now I am leading a group back in Germany that combines synthetic inorganic chemistry, quantum chemistry, and crystallography. In summary, I would say that I had a good intuition for an emerging field when I was thinking about postdoc possibilities.

Alessandro: My background is basically the opposite of Simon's. I was trained in quantum chemistry and I basically entered this field by chance. When I had to propose an original research project to apply for my current CNRS researcher position, I remembered that, some years before, my Ph.D. supervisor had shown me the papers written by Dylan Jayatilaka about the X-ray-constrained wave function approach. So, as for Simon, it was Dylan's work that got me interested in the field.

I decided to develop a project mainly based on the extension of the Jayatilaka technique to obtain "experimental" Extremely Localized Molecular Orbitals, with the final goal of using them to refine crystallographic structures of macromolecules. Until that moment, except for basic university classes, I had never really dealt with crystallography. Today-considering the promising perspectives offered by the evolving field of quantum crystallography-I assure you that I do not regret that choice.

\section{Thank you very much for the interview.}

\section{SHORT BIOGRAPHIES:}

Alessandro Genoni studied chemistry at the University of Milan, Italy, and received his Ph.D. there in 2006 under the supervision of Maurizio Sironi. After postdoctoral stays at the Quantum Theory Project of the University of Florida, Gainesville, USA, with Kenneth M. Merz Jr. from 2006 to 2008, and at the Institute for Molecular Recognition Chemistry of the CNR, Milan, Italy, with Giorgio Colombo from 2008 to 2011, he became CNRS Researcher at the University of Lorraine (currently at the Laboratory of Theoretical Physics and Chemistry, LPCT) in 2011. 
Simon Grabowsky studied chemistry at the Freie Universität Berlin, Germany, from 2001 to 2006 and received his Ph.D. there under the supervision of $\mathrm{P}$. Luger for experimental electron density work. After a postdoctoral stay at the University of Western Australia, Perth, he became Assistant Research Professor at the same university in 2014. In September 2014, Simon Grabowsky took on a temporary position as Emmy Noether group leader at the University of Bremen, Germany, and was awarded an extraordinary Professor title for the duration of his Emmy Noether project in 2015.

\section{Selected papers of}

\section{Simon Grabowsky and Alessandro Genoni:}

S. Grabowsky, A. Genoni, H.-B. Bürgi: Quantum crystallography. Chem. Sci. 2017, 8, 4159 - 4176.

\section{Simon Grabowsky:}

1) S. Grabowsky, P. Luger, J. Buschmann, T. Schneider, T. Schirmeister, A. N. Sobolev, D. Jayatilaka: The Significance of Ionic Bonding in Sulfur Dioxide: Bond Orders from X-ray Diffraction Data. Angew. Chem. Int. Ed. 2012, 51, 6776-6779.

2) S. C. Capelli, H.-B. Bürgi, B. Dittrich, S. Grabowsky, D. Jayatilaka: Hirshfeld atom refinement. IUCrJ 2014, 1, 361-379.

3) M. Woinska, S. Grabowsky, P. M. Dominiak, K. Wozniak, D. Jayatilaka: Hydrogen atoms can be located accurately and precisely by x-ray crystallography. Sci. Adv. 2016, 2, e1600192.

4) M. Fugel, J. Beckmann, D. Jayatilaka, G. V. Gibbs, S. Grabowsky: A variety of bond analysis methods, one answer? An investigation of the element-oxygen bond of hydroxides $\mathrm{H}_{n} \mathrm{XOH}$. Chem. Eur. J. 2018, 24, $6248-6261$.

\section{Alessandro Genoni:}

1) A. Genoni, Molecular Orbitals Strictly Localized on Small Molecular Fragments from X-ray Diffraction Data, J. Phys. Chem. Lett. 4, 1093-1099, 2013.

2) A. Genoni, X-ray Constrained Extremely Localized Molecular Orbitals: Theory and Critical Assessment of the New Technique, J. Chem. Theory Comput. 9, 3004-3019, 2013.

3) B. Meyer, B. Guillot, M. F. Ruiz-Lopez, A. Genoni, Libraries of Extremely Localized Molecular Orbitals. 1. Model Molecules Approximation and Molecular Orbitals Transferability, J. Chem. Theory Comput. 12, 1052-1067, 2016.

4) A. Genoni, L. H. R. Dos Santos, B. Meyer, P. Macchi, Can X-ray constrained Hartree-Fock wave functions retrieve electron correlation? IUCrJ 4, 136-146, 2017. 


\section{Researchers mentioned:}

Henry N. Chapman, Center for Free-Electron Laser Science, DESY, and University of Hamburg

Germany William L. Clinton, Georgetown University, Washington, D. C., USA

Philip Coppens, State University of New York at Buffalo, USA (Deceased)

Carlo Gatti, Istituto di Scienze e Tecnologie Molecolari - CNR, Italy

Dylan Jayatilaka, University of Western Australia, Australia

Piero Macchi, University of Bern, Switzerland

Louis J. Massa, Hunter College - City University of New York, USA

R. J. Dwayne Miller, Max Planck Institute for the Structure and Dynamics of Matter (MPSD) in Hamburg, Germany, and University of Toronto, Canada

Philip N. H. Nakashima, Monash University, Australia

Lukas Palatinus, The Czech Academy of Sciences, Czech Republic

Mark A. Spackman, University of Western Australia, Australia

Robert F. Stewart, Carnegie-Mellon University, Pittsburgh, USA (Deceased) 